\title{
Incidence, Risk Factors, and Treatment of Achilles Tendon Rupture in Patients with End-Stage Renal Disease
}

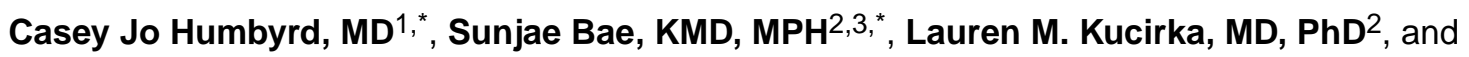 \\ Dorry L. Segev, MD, PhD ${ }^{2,3}$ \\ ${ }^{1}$ Department of Orthopaedic Surgery, The Johns Hopkins School of Medicine, Baltimore, MD \\ ${ }^{2}$ Department of Surgery, The Johns Hopkins School of Medicine, Baltimore, MD \\ ${ }^{3}$ Department of Epidemiology, The Johns Hopkins School of Public Health, Baltimore, MD
}

\begin{abstract}
Background-Dialysis-dependent patients and kidney transplant recipients may be at increased risk for Achilles tendon rupture (ATR).

Methods-We studied Medicare patients with ESRD from 1999 through 2013. Patients were categorized as waitlisted for a transplant, not waitlisted, or received a transplant. We performed multivariate negative binomial regression using demographic characteristics, comorbidities, and year of study entry to estimate adjusted incidence rate ratios (aIRRs), identify ATR risk factors, and determine treatment patterns and outcomes.
\end{abstract}

Results-We identified 1091 ATRs (incidence, 3.80/10,000 person-years; 95\% confidence interval [CI], 3.58-4.03). Compared with transplant recipients, non-waitlisted patients had lower incidence (aIRR, 0.44; 95\% CI, 0.37-0.53), and waitlisted patients had similar incidence (aIRR, 0.94; 95\% CI, 0.78-1.12) of ATR. ATR incidence was higher among patients taking fluoroquinolones (aIRR 1.65; 95\% CI, 1.32-1.84) and corticosteroids (aIRR 1.72; 95\% CI, 1.442.05) compared with those who did not. Patients with ATR were younger, had higher mean body mass index, and had fewer comorbidities than patients without ATR. Seventeen percent of patients received operative treatment within 14 days of ATR diagnosis. The 30-day cumulative incidence of operative site infections was $6.5 \%$.

Conclusion-The incidence of ATR was higher among transplant recipients and waitlisted patients compared with non-waitlisted patients. Younger age, higher body mass index, fewer comorbidities, fluoroquinolone use, and corticosteroid use were risk factors for ATR. Patients were more likely to receive nonoperative than operative treatment for ATR. Those who underwent operative treatment had a low incidence of operative site infection.

Level of Evidence-Prognostic level III Comparative Study

\footnotetext{
Address all correspondence and reprint requests to: Dr. Casey J. Humbyrd, MD, Department of Orthopaedic Surgery, The Johns Hopkins University/The Johns Hopkins Bayview Medical Center, 4940 Eastern Avenue, Suite A660B, Baltimore, MD 21224 (Telephone: 410-550-0452; casey.humbyrd@jhu.edu).

These authors contributed equally to the manuscript.

Declaration of Conflicting Interests: The author(s) declared no potential conflicts of interest with respect to the research, authorship, and/or publication of thisarticle.
} 


\section{Keywords}

Achilles tendon rupture; dialysis; end-stage renal disease; kidney transplant

\section{INTRODUCTION}

The incidence of Achilles tendon rupture (ATR) in the general population is 7-13 per 100,000 person-years ${ }^{19,20,34}$. ATRs typically occur in young or middle-aged sporadic athletes or "weekend warriors" as individuals maintain their athletic pursuits later in life ${ }^{13,18}$. There is also evidence of decreasing rates of operative treatment, likely related to high-quality trials showing the equivalence of operative and nonoperative treatments for acute ATR ${ }^{13,23,32}$.

It has been suggested that patients with end-stage renal disease (ESRD) are at greater risk of ATR. An association between kidney disease and spontaneous ATR has been documented in many case reports $3,4,11,17,33$. Corticosteroid and fluoroquinolone use are known risk factors for tendon rupture, and both of these medications are commonly prescribed for patients with kidney disease or after a kidney transplant ${ }^{5,31}$. Additionally, chronic kidney disease and maintenance dialysis create multiple metabolic abnormalities, particularly hyperparathyroidism, that appear to increase the risk for tendon rupture ${ }^{15}$.

The epidemiology of ATR in the ESRD population has not been fully characterized. There are potential differences in causes of, risk factors for, and treatment of ATR in the general population versus the ESRD population. The lifetime risk of advanced chronic kidney disease and ESRD is high and expected to rise with the aging population ${ }^{9}$; therefore, an understanding of ATR in this population is important. We speculate that these conditions may influence the orthopaedic surgeon's choice of treatment of ATR in ESRD patients. Per American Academy of Orthopaedic Surgeons Clinical Practice Guidelines, both operative and nonoperative treatments are options for acute ATR; however, clinicians may hesitate to perform surgery, particularly for ESRD patients. It is unclear whether ESRD is a valid contraindication for surgery.

We conducted an epidemiological study using a comprehensive national registry database of ESRD patients. Our goals were to: 1) estimate the incidence of ATR in the ESRD population, 2) identify associated risk factors (i.e., age, sex, race, body mass index, cause of ESRD, and comorbidities), and 3) describe treatment type and incidence of operative site infection (SSI) among patients with ESRD. We hypothesized that patients waitlisted for transplant would be less likely to undergo operative repair of ATR than non-waitlisted patients because surgery could harm their chances for a transplant. We also hypothesized that the rates of surgery would decrease during the study period, according to documented trends of decreasing rates of operative intervention after publication of randomized controlled trials demonstrating the effectiveness of nonoperative treatment ${ }^{23}$. 


\section{METHODS}

This study was deemed exempt from formal review by our institutional review board. All data were retrieved from the United States Renal Data System, a national registry of all patients with ESRD in the United States. We included all patients with ESRD who used Medicare Part A and B as their primary health insurance between January 1, 1999, and December 31, 2013. Demographic and comorbidity data were ascertained through the End Stage Renal Disease Medical Evidence Report, Medicare Entitlement and/or Patient Registration (form CMS-2728-U3), which must be filed for all patients within 45 days of an ESRD diagnosis. All patients were studied from their development of ESRD until death, end of Medicare primary coverage, or end of the study. Death was ascertained via the Social Security Death Master File.

\section{Dialysis vs. Transplantation}

Patients were categorized into the following 3 groups: 1 ) non-waitlisted (not on the transplant waitlist, never received a transplant), 2) waitlisted (on the transplant waitlist), or 3) transplant recipient ("transplanted"). Patients contributed time-at-risk in a time-varying manner in regression models. Patients could contribute person-time to multiple groups. For example, a patient on the waitlist for 2 years who then lived for 5 years after a transplant would contribute 2 and 5 years to the waitlisted and transplanted categories, respectively.

Patients were categorized in this way to help distinguish whether group differences in outcomes were the result of having undergone a transplant as opposed to selection bias. Patients who are waitlisted for a transplant or receive a transplant are typically healthier than patients not yet waitlisted for a transplant. Additionally, many patients' comorbidities prevent them from being eligible for transplant consideration. These categories allowed comparisons between patients of similar health status, with transplant as an independent variable.

\section{Incidence of and Risk Factors for Achilles Tendon Rupture}

We used Medicare Institutional and Physician/Supplier claims data to ascertain ATR events. ESRD patients are eligible for Medicare regardless of age, and more than a half use Medicare as their primary health insurance ${ }^{30}$. The Medicaid claims of ESRD patients are incorporated into the United States Renal Data System Standard Analysis Files. ATRs were ascertained using International Classification of Diseases, Ninth Revision, Clinical Modification $^{25}$ (ICD-9-CM) diagnosis code 727.67 (nontraumatic rupture of Achilles tendon) and Current Procedural Terminology ${ }^{1}$ (CPT) codes 27650 (repair, primary, open or percutaneous, ruptured Achilles tendon) and 27652 (repair, primary, open or percutaneous, ruptured Achilles tendon; with graft). We estimated the crude incidence, defined as the number of ATRs divided by the total time-at-risk, and its $95 \%$ confidence interval, by using univariate negative binomial regression. We subsequently performed multivariate negative binomial regression to estimate the adjusted incidence rate ratio (aIRR) among nonwaitlisted, waitlisted, and transplanted groups and to identify risk factors for ATR. We included all potential confounders available in the database in our model: age, race, sex, body mass index (BMI) value, cause of ESRD, comorbidities (hypertension, diabetes, 
congestive heart failure, atherosclerosis, peripheral vascular disease, cerebrovascular accident, chronic obstructive pulmonary disease, cancer, smoking status, alcohol dependence, drug dependence, inability to ambulate, and inability to be transferred), and year of study entry.

\section{Treatment Modality}

Among those who sustained an ATR, the patients whose records indicated a code of CPT 27650 or 27652 within 14 days of ATR diagnosis were considered to have received operative treatment ${ }^{8}$. We performed multivariate logistic regression, including age, race, sex, BMI value, cause of ESRD, and year of study entry to estimate the adjusted odds ratio (aOR) for receiving operative vs. nonoperative treatment among non-waitlisted, waitlisted, and transplanted groups and to identify factors associated with receipt of operative treatment.

We also reviewed the Medicare inpatient claims of patients who sustained ATR to ascertain whether they were admitted to the hospital within 14 days of diagnosis. We conducted multivariate logistic regression using the same set of covariables as the previous model to compare the odds of hospital admission among groups.

\section{Fluoroquinolone and Corticosteroid Use}

To characterize the associations of fluoroquinolone and corticosteroid use with ATR, we reviewed Medicare Part D Prescription Drug Coverage claims of the study cohort. Because Medicare Part D coverage started in January 2006, this analysis was restricted to 544,185 individuals (50\%) with confirmed Medicare Part D enrollment until their last day of followup. We also reviewed the immunosuppression records of the transplanted group because corticosteroids are often used for maintenance immunosuppression, which is usually covered by Medicare Part A and B.

Use of fluoroquinolones and corticosteroids was treated as a time-varying exposure. That is, individuals were treated as unexposed until the first day of prescription and as exposed thereafter. Using the same method described above, we estimated the aIRR of ATR among non-waitlisted, waitlisted, and transplanted groups for those with Medicare Part D coverage. Then, we added fluoroquinolone/corticosteroid exposure as a covariable to examine whether exposure to the medications explains the differences in ATR incidence among nonwaitlisted, waitlisted, and transplanted groups. Lastly, we stratified the population by fluoroquinolone/corticosteroid exposure to compare the aIRRs among those who were exposed to fluoroquinolones/corticosteroids versus those who were unexposed.

\section{Operative Site Infection}

Among patients who underwent operative treatment for ATR, we ascertained the incidence of SSI using ICD-9-CM code 998.59 (other postoperative infection). Patients whose records indicated this code within 30 days of the initial ATR diagnosis were considered to have developed a SSI. 


\section{Statistical Analyses}

We compared baseline characteristics using Student $t$ tests for continuous variables and chisquare tests for categorical variables. BMI values were missing for $8.7 \%$ of patients. These missing values were treated with a missingness indicator. Alpha level was set to 0.05 . All analyses were conducted using Stata/MP for Unix, version 14.2, software (StataCorp LP, TX).

\section{RESULTS}

\section{Study Population}

We identified 1091 ATRs during 2,870,817 person-years of follow-up. Patients who sustained an ATR were significantly younger (61 vs. 68 years) and more likely to be white, to have a higher BMI ( $29 \mathrm{vs.} 27 \mathrm{~kg} / \mathrm{m}^{2}$ ), to have diabetes or glomerulonephritis as the cause of ESRD ( $53 \%$ vs. $45 \%$ and $10 \%$ vs. $7.8 \%$, respectively), and to be ambulatory (5.7 vs. $2.6 \%$ nonambulatory) compared with uninjured patients (Table 1). Patients with ATR had fewer comorbidities than those without, with significantly lower prevalence of congestive heart failure, cancer, cerebrovascular accident, chronic obstructive pulmonary disease, hypertension, smoking, and atherosclerosis.

\section{Incidence of Achilles Tendon Rupture}

Overall, the crude incidence of ATR was 3.80 per 10,000 person-years (95\% confidence interval $[\mathrm{CI}], 3.58-4.03)$. The non-waitlisted group had a lower crude incidence $(2.91 ; 95 \%$ CI, 2.68-3.16) compared with that of the waitlisted (6.07; 95\% CI, 5.35-6.90) and transplanted groups $(5.22 ; 95 \% \mathrm{CI}, 4.66-5.85)$ (Table 2). After adjusting for confounders, the incidence was significantly lower in the non-waitlisted group compared with the transplanted group (aIRR, 0.44; 95\% CI, 0.37-0.53). The incidence was similar between the waitlisted and transplanted groups (aIRR, 0.94; 95\% CI, 0.78-1.12).

\section{Risk Factors for Achilles Tendon Rupture}

Non-white race, male sex, osteoporosis, and current smoker status were factors associated with a lower risk of ATR. Compared with underweight/normal BMI $\left(<25 \mathrm{~kg} / \mathrm{m}^{2}\right)$, higher BMI was associated with ATR in a dose-dependent manner. Patients with ESRD caused by diabetes mellitus were at higher risk for ATR compared with those with ESRD caused by glomerulonephritis. Peripheral vascular diseases and drug dependence were also risk factors for ATR (Table 3).

\section{Treatment Modality}

Of the 1091 patients who sustained ATR, 282 (26\% of all ATRs) were admitted to the hospital within 14 days after ATR diagnosis. Of these, 217 patients (77\% of admitted patients) had an ICD-9-CM or CPT code related to ATR, indicating that the reason for admission was related to the ATR as opposed to another cause. The non-waitlisted group was most likely to have ATR-related hospital admission (26\%), followed by the waitlisted group (19\%) and the transplanted group (9.4\%). These differences were statistically significant after adjusting for potential confounders. Compared with the transplanted group, 
the non-waitlisted group (aOR, 3.48; 95\% CI, 2.13-5.69) and the waitlisted group (aOR, 1.98; 95\% CI, 2.13-5.69) had higher odds of ATR-related hospital admission. There were no other significant predictors for ATR-related hospital admission for the variables studied, including age, race, BMI value, and cause of ESRD.

Only a small proportion of patients $(17 \%, \mathrm{~N}=184)$ received operative treatment within 14 days of ATR diagnosis. There were no significant differences in the probability of receiving operative treatment among the non-waitlisted (17\%), waitlisted (19\%), and transplanted (16\%) groups. Receipt of operative treatment was not associated with age, race, sex, BMI value, or cause of ESRD (Table 4).

The rate of surgery did not change during the study period. The rate ranged from a low of $8.3 \%$ in 2000 to a high of $27 \%$ in 1999 . In the most recent years of the study, the rate was $14 \%$ in 2010, 17\% in 2011 and 2012, and 19\% in 2013 (Figure 1).

\section{Fluoroquinolone and Corticosteroid Use}

In the subgroup of 544,185 individuals with Medicare Part D coverage, the overall crude incidence of ATR was 3.97 per 10,000 person-years (95\% CI, 3.69-4.29). After adjusting for confounders, we observed a significantly lower incidence in the non-waitlisted group compared with the transplanted group (aIRR, 0.51; 95\% CI, 0.40-0.65). The incidence was not significantly different in the waitlisted group compared with the transplanted group (aIRR, 0.88; 95\% CI, 0.71-1.10). These findings were comparable to those from the entire study population described above.

Fluoroquinolone exposure was associated with a significantly higher incidence of ATR (aIRR, 1.56; 95\% CI, 1.32-1.84). However, the IRRs of the non-waitlisted, waitlisted, and transplanted groups remained similar even after controlling for fluoroquinolone exposure (Supplementary Table), suggesting that the higher incidence of ATR in the waitlisted and transplanted groups was unlikely attributable to fluoroquinolone exposure. When stratified by fluoroquinolone exposure, the non-waitlisted group had a significantly lower incidence of ATR compared with the transplanted group among exposed patients (aIRR, $0.52 ; 95 \% \mathrm{CI}$, $0.37-0.71$ ) and unexposed patients (aIRR, 0.52; 95\% CI, 0.39-0.69). The incidence was not significantly different between the waitlisted and the transplanted groups among exposed patients (aIRR, 1.13; 95\% CI, 0.82-1.56) and unexposed patients (aIRR, 0.77; 95\% CI, $0.58-1.03)$.

Corticosteroid exposure was associated with significantly higher incidence of ATR (aIRR, $1.72 ; 95 \%$ CI, 1.44-2.05). Both of the IRRs (non-waitlisted versus transplanted and waitlisted versus transplanted) increased slightly after controlling for corticosteroid exposure (Supplementary Table). Moreover, when stratified by corticosteroid exposure, the nonwaitlisted group had a significantly lower incidence of ATR compared with the transplanted group among exposed patients (aIRR, $0.60 ; 95 \%$ CI, 0.45-0.81) but not among unexposed patients (aIRR, $0.78 ; 95 \% \mathrm{CI}, 0.45-1.35$ ). The waitlisted group had a significantly higher incidence of ATR compared with the transplanted group among exposed patients (aIRR, $1.51 ; 95 \%$ CI, 1.14-2.00) but not among unexposed patients (aIRR, 1.04; 95\% CI, 0.60- 
1.81). That is, the differences in ATR incidence between ESRD treatment groups were observed only among those exposed to corticosteroids.

\section{Operative Site Infections}

The 30-day cumulative incidence of SSIs was low (6.5\%). Seven non-waitlisted patients (7.5\%), 2 waitlisted patients (4.5\%), and 3 transplant recipients (6.4\%) had an SSI. These numbers were too low to allow statistical comparison.

\section{DISCUSSION}

In this national registry study, we examined ATRs in ESRD patients during 2,870,817 person-years of follow-up and found an overall incidence of 3.80 per 10,000 person-years. We observed a higher incidence of ATR among waitlisted patients (6.07 per 10,000 personyears) and transplant recipients (5.22 per 10,000 person-years) compared with nonwaitlisted patients (2.91 per 10,000 person-years). These differences persisted after adjustment for potential confounders.

There were no significant differences in ATR rates between waitlisted patients and transplant recipients. This suggests that the steroids and immunosuppressive medications taken by patients after transplant do not substantially increase the risk of ATR. A second possibility is that the transplant medications and metabolic abnormalities of dialysis are equally deleterious to the Achilles tendon, leading to similar rupture rates in similarly active patients.

The risk factors for ATR identified in our study differ from those in the general population. The risk of ATR was higher in women than men. This is in contrast to studies of the general population, which reported a higher risk in men $12,16,19,20,22,24,28,34$ or no difference between the sexes ${ }^{8}$. ATR incidence was also higher in white patients than black patients. Studies of military personnel have shown a greater risk of ATR in black patients than in those of other races $^{6,35}$. This discordance may suggest that the cause of ATR in patients with ESRD is different from the cause in the general population. ATR typically occurs in "weekend warriors" playing recreational sports. We speculate that ATR in the ESRD population is less attributable to sports and more attributable to other factors such as metabolic abnormality ${ }^{21,27}$, use of fluoroquinolones and steroids ${ }^{5,31}$, lower levels of regular physical activity $^{2}$, or preinjury tendinosis ${ }^{14,36}$.

Although there is evidence supporting both operative and nonoperative treatment, less than $20 \%$ of the patients in our study were treated operatively. In another study of Medicare patients with ATR, nearly $30 \%$ of patients older than 65 years were treated operatively ${ }^{8}$. Our findings suggest that surgeons may favor nonoperative treatment for patients with ESRD. However, whether ESRD is a true contraindication for surgery is unknown.

We hypothesized that waitlisted patients would be less likely to receive surgery because surgery could harm their chances for a transplant. For example, patients who undergo surgery and develop SSI may be prevented from receiving a transplant because of active 
infection ${ }^{26}$. Our results do not support this hypothesis. The rates of surgery for the waitlisted and transplanted groups were similar.

The rates of surgery did not change significantly during the study period. This is in contrast to our hypothesis that operative rates would decrease in response to studies showing equivalence between nonoperative and operative treatment. Such a decrease has been documented in the general population ${ }^{23}$. It is difficult to determine why operative rates did not decrease over time for patients with ESRD. It is possible that the rates were already so low that the new evidence of the equivalence of nonoperative treatment had little effect.

Other studies have found an association of ATR with fluoroquinolone use and corticosteroid use $^{5,31}$. The use of fluoroquinolones and corticosteroids in the ESRD population explains, at least in part, the higher incidence of ATR in this population. However, fluoroquinolone use did not seem to be responsible for the higher ATR rates in the waitlisted and transplant patients relative to the non-waitlisted patients.

Approximately $70 \%$ of transplant recipients take corticosteroids for maintenance immunosuppression ${ }^{10}$, and this is likely one reason for the higher ATR incidence observed among transplanted patients compared with non-waitlisted patients. It is unclear why the waitlisted patients exposed to corticosteroids had an even higher incidence of ATR compared with transplanted patients. This is the only covariable that was significantly different between these 2 populations. It is possible that the combination of higher activity (compared with non-waitlisted patients), dialysis, and corticosteroid use compounds risk.

A recent study showed that medical comorbidities were associated with significantly higher risk of infection after ATR repair, with an SSI incidence of $18 \%$ for those with a comorbidity compared with $6 \%$ for those without ${ }^{7}$. In our study, the risk of SSI for ESRD patients was low, with a 30-day cumulative incidence of $6.5 \%$. It is possible that the patients in our cohort who underwent surgery were the healthiest patients of the cohort, which may account for their lower complication rate.

The biggest strength of our study is that we drew from a large, representative sample of the target population using a mandatory national registry. Patients with ESRD are eligible for Medicare regardless of their age, and approximately $60 \%$ use Medicare as their primary payer $^{29}$. Using a data linkage between ESRD registrations and Medicare claims, we were able to study all Medicare patients with ESRD from 1999 through 2013. This study also has several limitations. First, we used administrative codes to ascertain outcomes. The validity of these administrative codes has not been established. However, because our methods are similar to those of a previous study of the general population ${ }^{8}$, it is unlikely that the use of administrative codes would have biased our findings. Second, data on some covariables such as physical function and routine physical activity were unavailable in our data source. Third, in an effort to limit our analysis to acute injuries, we limited our analysis of surgical intervention to the first 14 days after ATR diagnosis. It is possible that this approach resulted in an underestimation of surgical repairs of ATR. Finally, we ascertained the incidence of SSI using ICD-9-CM code 998.59 (other postoperative infection), which is the only code specific for postoperative infection. It is possible that postoperative infections were coded 
using different ICD-9-CM codes, and our use of a code specific for SSI underestimates the true infection rate.

We found notably higher ATR rates in the ESRD population compared with previous studies of the general population and the Medicare population. The rate for dialysis-dependent patients not waitlisted for transplant was almost half the rates for dialysis-dependent patients waitlisted for transplant and patients after transplant. White, female patients and those with higher BMI were more likely to sustain ATR. Patients with diabetes mellitus as the cause of ESRD had higher rates of rupture than did patients with ESRD from other causes. Patients with hypertension, congestive heart failure, cerebrovascular accident, chronic obstructive pulmonary disease, cancer, atherosclerosis, current smoking, and inability to ambulate were less likely to sustain ATR. Similar to the general population, ESRD patients treated with fluoroquinolones and/or corticosteroids were more likely to sustain ATR than patients not treated with these medications.

Most ESRD patients with ATRs were treated nonoperatively, but those treated with surgery had SSI rates similar to those of the general population. However, the rates of operative treatment were quite low, making it likely that only the healthiest and most active patients underwent surgery. These results suggest that ESRD should be considered a risk factor when contemplating surgery but not an absolute contraindication.

\section{Supplementary Material}

Refer to Web version on PubMed Central for supplementary material.

\section{Acknowledgments}

Source of Funding: This work was supported by the National Institute of Diabetes and Digestive and Kidney Diseases (grants K24DK101828 to DLS and F30DK095545). The data reported here were supplied by the United States Renal Data System. The interpretation and reporting of these data are the responsibility of the author(s) and in no way should be seen as an official policy or interpretation of the US government.

Funding Information:

U.S. Department of Health and Human Services >

National Institutes of Health >

\section{References}

1. American Medical Association. Current Procedural Terminology: CPT 2016. Chicago (IL): American Medical Association; 2016.

2. Aucella F, Valente GL, Catizone L. The role of physical activity in the CKD setting. Kidney Blood Press Res. 2014; 39(2-3):97-106. DOI: 10.1159/000355783 [PubMed: 25117619]

3. Basic-Jukic N, Juric I, Racki S, Kes P. Spontaneous tendon ruptures in patients with end-stage renal disease. Kidney Blood Press Res. 2009; 32(1):32-36. DOI: 10.1159/000201792 [PubMed: 19212123]

4. Bradlow A, Thompson JF, Morris PJ, Watson NA. Multiple spontaneous ruptures of tendons in renal transplant recipient. Br Med J (Clin Res Ed). 1984; 288(6414):364-365.

5. Claessen FM, de Vos RJ, Reijman M, Meuffels DE. Predictors of primary Achilles tendon ruptures. Sports Med. 2014; 44(9):1241-1259. DOI: 10.1007/s40279-014-0200-z [PubMed: 24929701] 
6. Davis JJ, Mason KT, Clark DA. Achilles tendon ruptures stratified by age, race, and cause of injury among active duty U.S. Military members. Mil Med. 1999; 164(12):872-873. [PubMed: 10628159]

7. Dombrowski, ME., Murawski, CD., Yasui, Y., et al. Co-morbidities are associated with increased cost, infection rates, and duration of treatment after primary Achilles tendon repair; Presented at the AOFAS Annual Meeting; Toronto, Ontario. July 20-23, 2016;

8. Erickson BJ, Cvetanovich GL, Nwachukwu BU, et al. Trends in the management of Achilles tendon ruptures in the United States Medicare population, 2005-2011. Orthop J Sports Med. 2014; 2(9) 2325967114549948. doi: 10.1177/2325967114549948

9. Grams ME, Chow EK, Segev DL, Coresh J. Lifetime incidence of CKD stages 3-5 in the United States. Am J Kidney Dis. 2013; 62(2):245-252. DOI: 10.1053/j.ajkd.2013.03.009 [PubMed: 23566637]

10. Hart A, Smith JM, Skeans MA, et al. OPTN/SRTR 2015 Annual data report: Kidney. Am J Transplant. 2017; 17(Suppl 1):21-116. DOI: 10.1111/ajt.14124 [PubMed: 28052609]

11. Hestin D, Mainard D, Pere P, et al. Spontaneous bilateral rupture of the Achilles tendons in a renal transplant recipient. Nephron. 1993; 65(3):491-492. [PubMed: 8290013]

12. Houshian S, Tscherning T, Riegels-Nielsen P. The epidemiology of Achilles tendon rupture in a Danish county. Injury. 1998; 29(9):651-654. [PubMed: 10211195]

13. Huttunen TT, Kannus P, Rolf C, et al. Acute achilles tendon ruptures: incidence of injury and surgery in Sweden between 2001 and 2012. Am J Sports Med. 2014; 42(10):2419-2423. DOI: 10.1177/0363546514540599 [PubMed: 25056989]

14. Jarvinen TA, Kannus P, Maffulli N, Khan KM. Achilles tendon disorders: etiology and epidemiology. Foot Ankle Clin. 2005; 10(2):255-266. [PubMed: 15922917]

15. Jones N, Kjellstrand CM. Spontaneous tendon ruptures in patients on chronic dialysis. Am J Kidney Dis. 1996; 28(6):861-866. [PubMed: 8957038]

16. Jozsa L, Kvist M, Balint BJ, et al. The role of recreational sport activity in Achilles tendon rupture. A clinical, pathoanatomical, and sociological study of 292 cases. Am J Sports Med. 1989; 17(3): 338-343. [PubMed: 2729483]

17. Kato A, Ishigaki S, Yasuda H. Levofloxacin-associated Achilles tendinitis in a patient with chronic kidney disease stage 5. Clin Exp Nephrol. 2011; 15(2):318-319. DOI: 10.1007/ s10157-011-0417-1 [PubMed: 21327696]

18. Lantto I, Heikkinen J, Flinkkila T, et al. Epidemiology of Achilles tendon ruptures: increasing incidence over a 33-year period. Scand J Med Sci Sports. 2015; 25(1):e133-138. DOI: 10.1111/ sms.12253 [PubMed: 24862178]

19. Leppilahti J, Puranen J, Orava S. Incidence of Achilles tendon rupture. Acta Orthop Scand. 1996; 67(3):277-279. [PubMed: 8686468]

20. Levi N. The incidence of Achilles tendon rupture in Copenhagen. Injury. 1997; 28(4):311-313. [PubMed: 9282189]

21. Lui PPY. Tendinopathy in diabetes mellitus patients-Epidemiology, pathogenesis, and management. Scand J Med Sci Sports. 2017; 27(8):776-787. DOI: 10.1111/sms.12824 [PubMed: 28106286]

22. Maffulli N, Waterston SW, Squair J, et al. Changing incidence of Achilles tendon rupture in Scotland: a 15-year study. Clin J Sport Med. 1999; 9(3):157-160. [PubMed: 10512344]

23. Mattila VM, Huttunen TT, Haapasalo H, et al. Declining incidence of surgery for Achilles tendon rupture follows publication of major RCTs: evidence-influenced change evident using the Finnish registry study. Br J Sports Med. 2015; 49(16):1084-1086. DOI: 10.1136/bjsports-2013-092756 [PubMed: 24128757]

24. Moller A, Astron M, Westlin N. Increasing incidence of Achilles tendon rupture. Acta Orthop Scand. 1996; 67(5):479-481. [PubMed: 8948254]

25. National Center for Health Statistics; Centers for Medicare and Medicaid Services. ICD-9-CM: International Classification of Diseases, 9th revision, Clinical Modification. Washington, DC: Department of Health and Human Services; 2010.

26. National Kidney Foundation. [Accessed August 11, 2017] The kidney transplant waitlist-what you need to know. Available at https://www.kidney.org/atoz/content/transplant-waitlist 
27. Partridge L, Rajbhandari S. Achilles Tendon in Diabetes. Curr Diabetes Rev. 2017; 13(4):424-427. DOI: 10.2174/1573399812666160620100616 [PubMed: 27333801]

28. Raikin SM, Garras DN, Krapchev PV. Achilles tendon injuries in a United States population. Foot Ankle Int. 2013; 34(4):475-480. DOI: 10.1177/1071100713477621 [PubMed: 23386750]

29. Saran R, Robinson B, Abbott KC, et al. US renal data system 2016 annual data report: Epidemiology of kidney disease in the United States. Am J Kidney Dis. 2017; 69(3 Suppl 1):A7a8. DOI: 10.1053/j.ajkd.2016.12.004 [PubMed: 28236831]

30. Saran R, Robinson B, Abbott KC, et al. US Renal Data System 2016 Annual Data Report: Epidemiology of Kidney Disease in the United States. Am J Kidney Dis. 2017; 69(3S1):A7-A8. DOI: 10.1053/j.ajkd.2016.12.004 [PubMed: 28236831]

31. Sode J, Obel N, Hallas J, Lassen A. Use of fluroquinolone and risk of Achilles tendon rupture: a population-based cohort study. Eur J Clin Pharmacol. 2007; 63(5):499-503. DOI: 10.1007/ s00228-007-0265-9 [PubMed: 17334751]

32. Soroceanu A, Sidhwa F, Aarabi S, et al. Surgical versus nonsurgical treatment of acute Achilles tendon rupture: a meta-analysis of randomized trials. J Bone Joint Surg Am. 2012; 94(23):21362143. DOI: 10.2106/jbjs.k.00917 [PubMed: 23224384]

33. Spencer JD. Spontaneous rupture of tendons in dialysis and renal transplant patients. Injury. 1988; 19(2):86-88. [PubMed: 3058609]

34. Suchak AA, Bostick G, Reid D, et al. The incidence of Achilles tendon ruptures in Edmonton, Canada. Foot Ankle Int. 2005; 26(11):932-936. DOI: 10.1177/107110070502601106 [PubMed: 16309606]

35. White DW, Wenke JC, Mosely DS, et al. Incidence of major tendon ruptures and anterior cruciate ligament tears in US Army soldiers. Am J Sports Med. 2007; 35(8):1308-1314. DOI: 10.1177/0363546507301256 [PubMed: 17468380]

36. Yasui Y, Tonogai I, Rosenbaum AJ, et al. The Risk of Achilles Tendon Rupture in the Patients with Achilles Tendinopathy: Healthcare Database Analysis in the United States. Biomed Res Int. 2017; 2017:7021862.doi: 10.1155/2017/7021862 [PubMed: 28540301] 


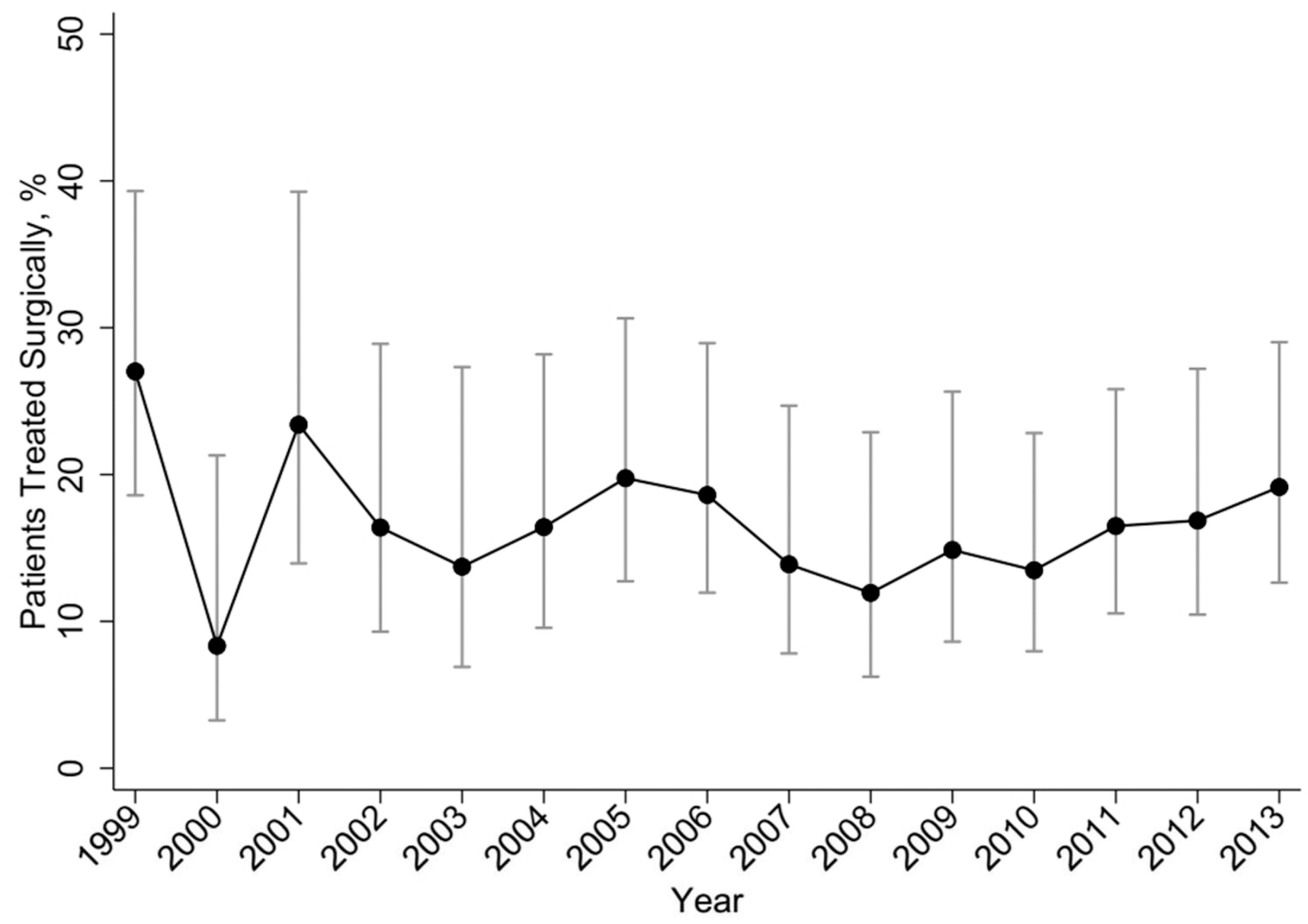

Figure 1.

Proportion of 1091 patients with end-stage renal disease treated operatively for Achilles tendon rupture, 1999-2013. Bars indicate 95\% confidence intervals. 
Table 1

Characteristics of Patients with ESRD, US Renal Data System and Centers for Medicare \& Medicaid Services, 1999-2013

\begin{tabular}{|c|c|c|c|}
\hline Characteristic & $\begin{array}{c}\text { Patients with ATR, \% } \\
(\mathrm{N}=1,091)\end{array}$ & $\begin{array}{c}\text { Patients without ATR, \% } \\
(\mathrm{N}=\mathbf{1 , 0 8 6 , 7 1 0 )}\end{array}$ & P Value \\
\hline Age, y & $61(50-70)^{*}$ & $68(57-77)^{*}$ & $<.001$ \\
\hline Male sex & $606(55.5)$ & $598,448(55.1)$ & .75 \\
\hline \multicolumn{4}{|l|}{ Race } \\
\hline White & $772(70.8)$ & $732,790(67.4)$ & \multirow{3}{*}{.005} \\
\hline Black & $279(25.6)$ & $291,873(26.9)$ & \\
\hline Other & $40(3.7)$ & $62,047(5.7)$ & \\
\hline Body mass index, $\mathrm{kg} / \mathrm{m}^{2}$ & $28.8(24.6-33.5)^{*}$ & $26.6(22.9-31.5)^{*}$ & $<.001$ \\
\hline \multicolumn{4}{|l|}{ Cause of ESRD } \\
\hline Diabetes mellitus & $580(53.2)$ & $484,009(44.5)$ & \multirow{4}{*}{$<.001$} \\
\hline Hypertension & $111(10.2)$ & $84,317(7.8)$ & \\
\hline Glomerulonephritis & $222(20.3)$ & $310,602(28.6)$ & \\
\hline Other/missing & $178(16.3)$ & $207,782(19.1)$ & \\
\hline \multicolumn{4}{|l|}{ Comorbidities } \\
\hline Hypertension & $809(75.0)$ & $849,504(79.3)$ & $<.001$ \\
\hline Diabetes & $599(55.5)$ & $546,906(51.0)$ & .003 \\
\hline Congestive heart failure & $262(24.3)$ & $345,180(32.2)$ & $<.001$ \\
\hline Atherosclerosis & $230(21.3)$ & $265,927(24.8)$ & .008 \\
\hline Peripheral vascular disease & $154(14.3)$ & $154,510(14.4)$ & .89 \\
\hline Cerebrovascular accident & $69(6.4)$ & $102,931(9.6)$ & $<.001$ \\
\hline COPD & $57(5.3)$ & $93,805(8.8)$ & $<.001$ \\
\hline Cancer & $38(3.5)$ & $71,196(6.6)$ & $<.001$ \\
\hline Current smoker & $34(3.2)$ & $49,812(4.6)$ & .020 \\
\hline Cannot ambulate & $28(2.6)$ & $61,442(5.7)$ & $<.001$ \\
\hline Cannot be transferred & $13(1.2)$ & $28,554(2.7)$ & .003 \\
\hline Alcohol dependence & $11(1.0)$ & $10,662(1.0)$ & .93 \\
\hline Drug dependence & $10(0.9)$ & $5,812(0.5)$ & .086 \\
\hline
\end{tabular}

ATR, Achilles tendon rupture; COPD, chronic obstructive pulmonary disease; ESRD, end-stage renal disease.

* Data presented as mean (range).

Foot Ankle Int. Author manuscript; available in PMC 2019 July 01. 


\section{Table 2}

Crude Incidence of ATR from 2,870,817 Person-Years of Follow-up in Patients with End-Stage Renal Disease, US Renal Data System and Centers for Medicare \& Medicaid Services, 1999-2013

\begin{tabular}{|l|c|c|c|}
\hline Patient Group & $\begin{array}{c}\text { No. of } \\
\text { ATRs }\end{array}$ & $\begin{array}{c}\text { Follow-up, } \\
\text { Person-Years }\end{array}$ & $\begin{array}{c}\text { ATRs per 10,000 Person-Years } \\
\text { (95\% Confidence Interval) }\end{array}$ \\
\hline Non-waitlisted, dialysis-dependent & 555 & $1,907,626$ & $2.91(2.68-3.16)$ \\
\hline Waitlisted, dialysis-dependent & 237 & 390,204 & $6.07(5.35-6.90)$ \\
\hline Transplanted & 299 & 572,986 & $5.22(4.66-5.85)$ \\
\hline Overall & 1091 & $2,870,817$ & $3.80(3.58-4.03)$ \\
\hline
\end{tabular}

ATR, Achilles tendon rupture 
Table 3

Risk Factors for Achilles Tendon Rupture in Patients with ESRD, US Renal Data System and Centers for Medicare \& Medicaid Services, 1999-2013

\begin{tabular}{|c|c|c|}
\hline Parameters & Adjusted IRR (95\% CI) & P Value \\
\hline \multicolumn{3}{|l|}{ ESRD treatment } \\
\hline Transplanted & Referent & \\
\hline Nonwaitlisted & $0.44(0.37-0.53)$ & $<.001$ \\
\hline Waitlisted & $0.94(0.78-1.12)$ & .5 \\
\hline \multicolumn{3}{|l|}{ Age group, y } \\
\hline $0-49$ & $0.93(0.76-1.14)$ & .5 \\
\hline $50-64$ & $1.11(0.93-1.33)$ & .3 \\
\hline $65-69$ & Referent & \\
\hline $70-100$ & $0.88(0.73-1.07)$ & .2 \\
\hline \multicolumn{3}{|l|}{ Race } \\
\hline White & Referent & \\
\hline Black & $0.65(0.57-0.75)$ & $<.001$ \\
\hline Other & $0.46(0.33-0.63)$ & $<.001$ \\
\hline \multicolumn{3}{|l|}{ Sex } \\
\hline Female & Referent & \\
\hline Male & $0.75(0.66-0.85)$ & $<.001$ \\
\hline \multicolumn{3}{|l|}{ Body mass index, $\mathrm{kg} / \mathrm{m}^{2}$} \\
\hline $0-24.99$ & Referent & \\
\hline $25.00-29.99$ & $1.25(1.05-1.49)$ & .01 \\
\hline $30.00-39.99$ & $1.56(1.31-1.85)$ & $<.001$ \\
\hline$\geq 40$ & $1.81(1.41-2.31)$ & $<.001$ \\
\hline \multicolumn{3}{|l|}{ Cause of ESRD } \\
\hline Glomerulonephritis & Referent & \\
\hline Diabetes mellitus & $1.43(1.16-1.78)$ & .001 \\
\hline Hypertension & $0.95(0.75-1.20)$ & .6 \\
\hline Other/missing & $0.95(0.75-1.21)$ & .7 \\
\hline \multicolumn{3}{|l|}{ Comorbidities } \\
\hline Drug dependence & $2.04(1.07-3.92)$ & .03 \\
\hline Peripheral vascular disease & $1.34(1.12-1.61)$ & .002 \\
\hline Alcohol dependence & $1.27(0.68-2.36)$ & .4 \\
\hline Atherosclerosis & $1.09(0.93-1.28)$ & .3 \\
\hline COPD & $0.94(0.71-1.24)$ & .7 \\
\hline Congestive heart failure & $0.89(0.76-1.04)$ & .1 \\
\hline Cancer & $0.89(0.64-1.23)$ & .5 \\
\hline Cerebrovascular accident & $0.85(0.66-1.09)$ & .2 \\
\hline Current smoker & $0.68(0.48-0.97)$ & .03 \\
\hline
\end{tabular}

Foot Ankle Int. Author manuscript; available in PMC 2019 July 01. 


\begin{tabular}{|l|c|c|}
\hline Parameters & Adjusted IRR (95\% CI) & P Value \\
\hline Osteoporosis & $0.14(0.12-0.17)$ & $<.001$ \\
\hline
\end{tabular}

$\mathrm{CI}$, confidence interval; COPD, chronic obstructive pulmonary disease; ESRD, end-stage renal disease IRR, incidence rate ratio 
Table 4

Odds of ESRD Patients Receiving Operative Treatment for Achilles Tendon Ruptures within 14 Days of Injury, US Renal Data System and Centers for Medicare \& Medicaid Services, 1999-2013

\begin{tabular}{|c|c|c|}
\hline Parameters & Adjusted OR (95\% CI) & $P$ Value \\
\hline \multicolumn{3}{|l|}{ ESRD treatment } \\
\hline Transplanted & Referent & \\
\hline Nonwaitlisted & $1.52(0.97-2.39)$ & .1 \\
\hline Waitlisted & $1.35(0.83-2.20)$ & .2 \\
\hline \multicolumn{3}{|l|}{ Age group, y } \\
\hline $0-49$ & $1.53(0.92-2.54)$ & .1 \\
\hline $50-64$ & $1.08(0.66-1.76)$ & .8 \\
\hline $65-69$ & Referent & \\
\hline $70-100$ & $0.64(0.37-1.11)$ & .1 \\
\hline \multicolumn{3}{|l|}{ Race } \\
\hline White & Referent & \\
\hline Black & $1.04(0.71-1.52)$ & .9 \\
\hline Other & $0.36(0.11-1.22)$ & .1 \\
\hline \multicolumn{3}{|l|}{ Sex } \\
\hline Female & Referent & \\
\hline Male & $0.86(0.62-1.20)$ & .4 \\
\hline \multicolumn{3}{|c|}{ Body mass index, $\mathrm{kg} / \mathrm{m}^{2}$} \\
\hline $0-24.99$ & Referent & \\
\hline $25.00-29.99$ & $1.11(0.70-1.75)$ & .7 \\
\hline $30.00-39.99$ & $0.79(0.49-1.26)$ & .3 \\
\hline$\geq 40$ & $0.75(0.38-1.50)$ & .4 \\
\hline \multicolumn{3}{|l|}{ Cause of ESRD } \\
\hline Glomerulonephritis & Referent & \\
\hline Diabetes mellitus & $0.65(0.37-1.13)$ & .1 \\
\hline Hypertension & $0.55(0.29-1.03)$ & .1 \\
\hline Other/missing & $0.98(0.53-1.80)$ & .9 \\
\hline
\end{tabular}

CI, confidence interval; ESRD, end-stage renal disease; OR, odds ratio 